\title{
Effect of Silicon Content on Intergranular Embrittlement of Ferritic Spheroidal Graphite Cast Iron Suffered from Cyclic Heating
}

\author{
Hung-Mao Lin*1, Truan-Sheng Lui*2 and Li-Hui Chen \\ Department of Materials Science and Engineering, National Cheng Kung University, Tainan 701, Taiwan, R. O. China
}

The effect of silicon content on intergranular embrittlement of ferritic spheroidal graphite cast irons after suffer a certain number of thermal cycles is investigated. The tensile elongation tends to increase with the number of thermal cycles, and increased silicon content leads to eventual embrittlement. The fracture surface of a $2.9 \mathrm{Si}$ specimen changes from dimple pattern feature to intergranular fracture, whereas the fracture surfaces of both 4.0Si and 4.3Si specimens change from the brittle cleavage to intergranular fracture that following with increasing the number of thermal cycles. The intergranular cracking path will initiate and propagate through the eutectic cell boundaries due to the presence of microsegregated inclusions that clustered in the eutectic cell boundary region. These inclusions are oxides that mainly contain magnesium, phosphorus and cerium. Experimental analysis detected that the magnesium elements not only segregated in the vicinity of eutectic cell boundaries, but also the annealed ferritic grain boundaries. However the embrittlement resulted from cyclic heating is strongly dependent on the morphology of clustered inclusions and is pertaining to the variation of silicon content. The observed magnesium-containing inclusions located in the central region of the matrix may profoundly affect the overall tensile fracture behavior of heat resistant used SG cast irons.

(Received September 3, 2002; Accepted November 11, 2002)

Keywords: cyclic heating, spheroidal graphite cast iron, silicon content, intergranular fracture

\section{Introduction}

The microstructure and chemical composition of spheroidal graphite (SG) cast iron can be flexibly adjusted to acquire the expected heat resistance. Especially when components suffer cyclic heating, as do guide plates in hot rolling equipment, aluminum ingot molds or exhaust manifolds, they are periodically operated at a maximum heating temperature up to $900^{\circ} \mathrm{C}$.

The microstructural features of SG cast iron basically include a fair amount of heterogeneous graphite nodules which have a connection with the thermally induced stress or strain. Demands for better performance require that the common deterioration in reliability caused by cyclic heating should be overcome. Based on our previous reports, cyclic heating cracks are initiated from the surface where the solidificational eutectic cell boundary area is first damaged by oxidation, stress concentration and segregation effects. ${ }^{1,2)}$ The oxidization resistance and structural stability of SG cast irons are important factors that govern deterioration under repetitive heating/cooling. Therefore, high silicon ferritic SG cast irons are more suitable for applications at elevated temperatures, because silicon in cast irons not only promotes ferritization, but also raises the eutectoid temperature, thus improving high-temperature stability. ${ }^{3)}$

On the other hand, increasing silicon content causes more severe thermal stress on the surface and eutectic cell boundaries during the cyclic heating/cooling process. ${ }^{2,4,5}$ Our pervious report ${ }^{1)}$ confirmed that increasing the silicon content causes thermal cracking in the earlier stages of thermal cycling. This fact raises questions of how the solid solute silicon content affects thermal cracking behavior, and what roles the graphite nodules play during these demanding cyclic heating/cooling tests. Accordingly, our recent study on the effect of silicon content related to the tensile elongation and cyclic heating conditions are reported in detail below.

\footnotetext{
${ }^{* 1}$ Graduate Student, National Cheng Kung University.

${ }^{* 2}$ Corresponding author: E-mail: z7408020@email.ncku.edu.tw
}

\section{Experimental Procedure}

The carbon content of all specimens of SG cast irons used in this study, and listed in Table 1, was controlled within a range of 3.4-3.6 mass \% while the silicon content varied from 2.9 to 4.3 mass $\%$. Specimens were coded as $2.9 \mathrm{Si}$, 4.0Si and 4.3Si according to silicon content. The specimens were prepared by melting low-sulfur pig iron, ferrosilicon and scraps in a $100 \mathrm{~kg}$ induction furnace and pouring the melts into Y-shaped $\mathrm{CO}_{2}$ sand molds after spheroidizied by $\mathrm{Fe}-$ 45 mass $\% \mathrm{Si}-8$ mass $\% \mathrm{Mg}-2.5$ mass $\%$ RE spheroidizer ( 1.5 mass $\%$ additive amount) and inoculated by $\mathrm{Fe}-$ 48 mass $\%$ Si-6 mass \% Mg-2 mass\% RE inoculant (0.3 mass\% additive amount), to produce castings with the dimensions of $30 \mathrm{~mm} \times 100 \mathrm{~mm} \times 150 \mathrm{~mm}$ in the parallel section.

The ferritization procedure followed typical two-stage isothermal holding, in which all specimens were maintained at $930^{\circ} \mathrm{C}$ for $3 \mathrm{~h}$ in the first stage. The $4.0 \mathrm{Si}$ and $4.3 \mathrm{Si}$ specimens were maintained at $820^{\circ} \mathrm{C}$ for $5 \mathrm{~h}$ while the $2.9 \mathrm{Si}$ specimen was held at $730^{\circ} \mathrm{C}$ for $5 \mathrm{~h}$ in the second stage. The furnace was then cooled to room temperature. Specimens were etched with $5 \%$ nital solution and electrochemical Morries solution $\left(25 \mathrm{~g} \mathrm{CrO}_{3}: 133 \mathrm{~cm}^{3}\right.$ glacial acetic acid: $7 \mathrm{~cm}^{3} \mathrm{H}_{2} \mathrm{O}$ ), to verify the distribution and degree of clustering of cell boundary inclusions. Figures 1(a) to (d) display the optical microstructure of the test specimens.

For the tensile tests, round-type specimens with 25-mm gauge length and 5-mm gauge diameter were used. The initial strain rate was fixed at $3.3 \times 10^{-3} \mathrm{~s}^{-1}$. During the thermal cycling test, each specimen was cyclically immersed in an

Table 1 Chemical Composition of the SG Cast Irons used in this study.

\begin{tabular}{ccccccc}
\hline \multicolumn{7}{c}{ Composition (mass\%) } \\
\hline Material & $\mathrm{C}$ & $\mathrm{Si}$ & $\mathrm{Mn}$ & $\mathrm{P}$ & $\mathrm{S}$ & $\mathrm{Mg}$ \\
\hline $2.9 \mathrm{Si}$ & 3.65 & 2.91 & 0.058 & 0.044 & 0.009 & 0.052 \\
$4.0 \mathrm{Si}$ & 3.43 & 4.02 & 0.058 & 0.046 & 0.008 & 0.055 \\
$4.3 \mathrm{Si}$ & 3.54 & 4.29 & 0.063 & 0.051 & 0.012 & 0.058 \\
\hline
\end{tabular}




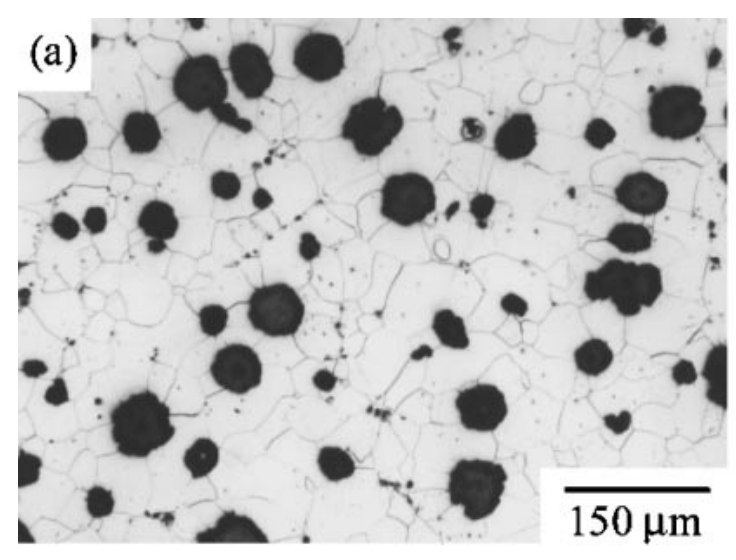

$$
\overline{\mathrm{d}}_{\mathrm{f}}: 43 \mu \mathrm{m}, \overline{\mathrm{d}}_{\mathrm{g}}: 40 \mu \mathrm{m}
$$

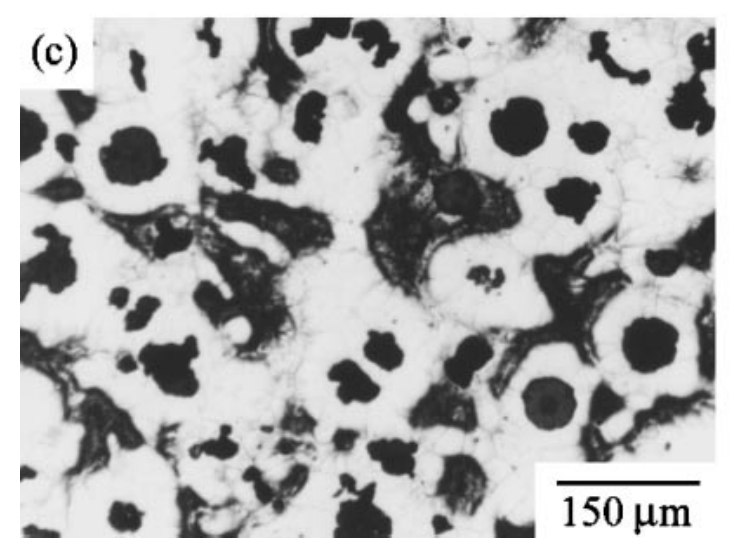

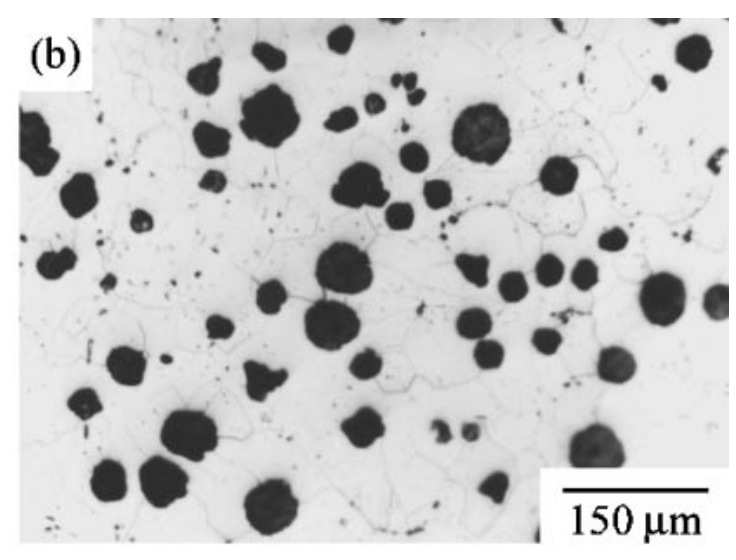

$\overline{\mathrm{d}}_{\mathrm{f}}: 40 \mu \mathrm{m}, \overline{\mathrm{d}}_{\mathrm{g}}: 32 \mu \mathrm{m}$

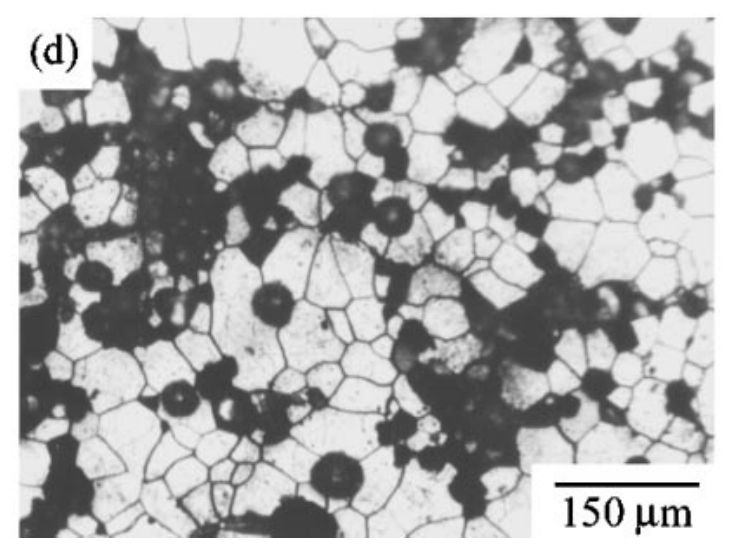

Fig. 1 Optical micrographs of the test specimens after 5\%nital etched: (a) 2.9Si; (b) 4.3Si and after electrochemically etched: (c) 2.9Si; (d) 4.3Si.

isothermal $700^{\circ} \mathrm{C}$ neutral salt bath for 3 min, water quenched to $25 \pm 5^{\circ} \mathrm{C}$ and air dried. After a certain number of thermal cycles, the specimens were tension-tested at room temperature and the test results were used to evaluate the extent of deterioration. The fracture surfaces were observed using scanning electron microscopy (SEM) and the observed inclusions and the intergranular fracture facets were analyzed with energy dispersive spectroscopy (EDS). The fracture surface analysis of both solidificational cell boundaries and annealed ferritic grain boundaries was performed with a scanning auger microprobe (SAM). Before SAM analysis, the specimens were machined with notch prior to perform insitu impact tested at $-50^{\circ} \mathrm{C}$ in a SAM vacuum chamber at $10^{-10} \mathrm{~Pa}$.

\section{Results}

\subsection{Effect of thermal cycles on embrittlement of SG cast irons}

Figure 1 shows that little differences in average graphite nodule size $\left(\bar{d}_{\mathrm{g}}\right)$, and ferrite grain size $\left(\bar{d}_{\mathrm{f}}\right)$ are observed with increasing silicon content. Figures $1(\mathrm{c})$ and (d) reveal the distribution of the inclusion particles around the eutectic cell walls, ${ }^{6,7)}$ the area of clustered inclusions can be identified by electrochemical etching. Compare to other samples, the 2.9Si specimen shows the least amount of inclusion particles in the eutectic cell wall regions, however the degree of inclusion clustering become significant as increasing silicon concentration. It should be noted that, though the inclusions evidently tend to increase with silicon content, the specific eutectic cell boundary area becomes smaller hence the inclusion tend to concentrate as observed in high silicon content specimens shown in Fig. 1(d). This result agrees well with the previous report depicted that increasing the silicon concentration can promote the rejection of the inclusion into liquid phase..$^{8)}$ Notably, the variation of above-mentioned microstructural feature is closely related to the solidification process and alloying elements.

Figure 2 shows a distinct deterioration of tensile elongation, the effect of heating cycles on the elongation is evident. For example, the 2.9Si sample before undergoing cyclic heating test originally exhibited $16 \%$ elongation, and the 4.0Si and 4.3Si specimens had over $12 \%$ elongation respectively, tensile elongation data tend to decrease as the number of thermal cycles increases.

Figure 3 shows the tensile fracture features of the specimens with different silicon contents before the cyclic heating tests, only the $2.9 \mathrm{Si}$ specimen demonstrates a completely ductile dimple pattern (Fig. 3(a)) while the 4.0Si specimen combines zoned ductile and brittle fractures (respectively dark and bright regions in Fig. 3(b)) and the 4.3Si specimen shows a completely brittle cleavage fracture 


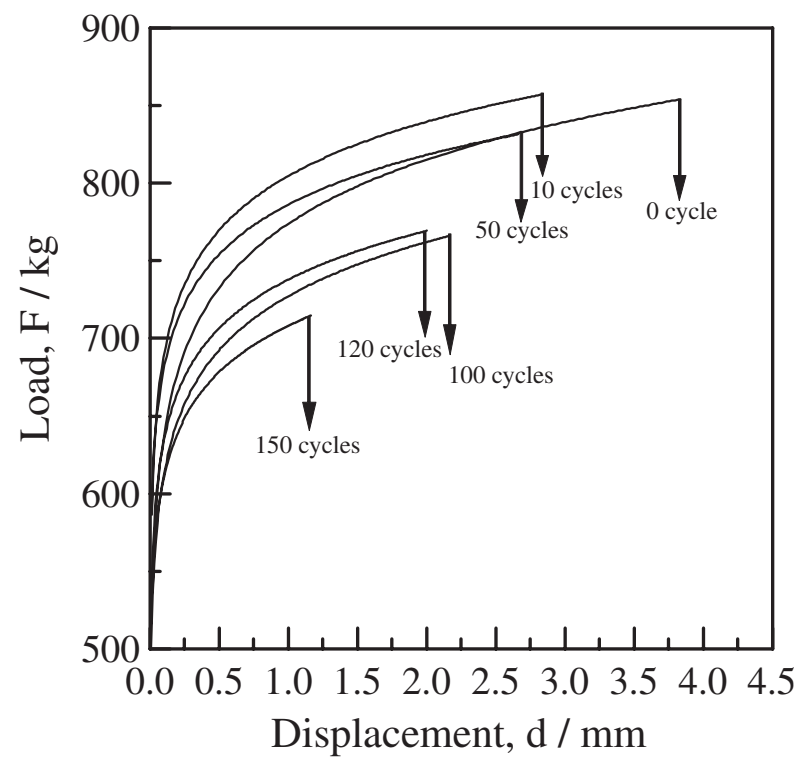

Fig. 2 The effect of cyclic heating on the dependence of load and displacement.
(Fig. 3(c)). This evidence indicates that the variation of fracture feature can be correlated with the increasing of silicon content.

Since the ductility deterioration depends strongly on the specific heating cycles, the deterioration after the specimen underwent a certain numbers of heating cycles should be reasonably clarified.

\subsection{Effect of silicon content on intergranular embrittle- ment after cyclic heating}

Firstly, the relationship between tensile elongation and the number of heating cycles is investigated to clarify the effects of silicon content on the occurrence of embrittlement. Tensile testing was conducted at room temperature and all specimens underwent an identical thermal cyclic test with maximum heating temperature of $700^{\circ} \mathrm{C}$. ${ }^{1)}$ The deterioration rate of tensile elongation after cyclic heating is defined as the deterioration rate $=1-\left(M_{\text {cycles }} / M_{0}\right) \quad\left(M_{0}\right.$ is the tensile elongation before cyclic heating; $M_{\text {cycles }}$ is the tensile elongation after a certain number of thermal cycles). Figure 4 presents the relationship between the elongation and the number of thermal cycles; however the silicon content greatly affects the tensile elongation.
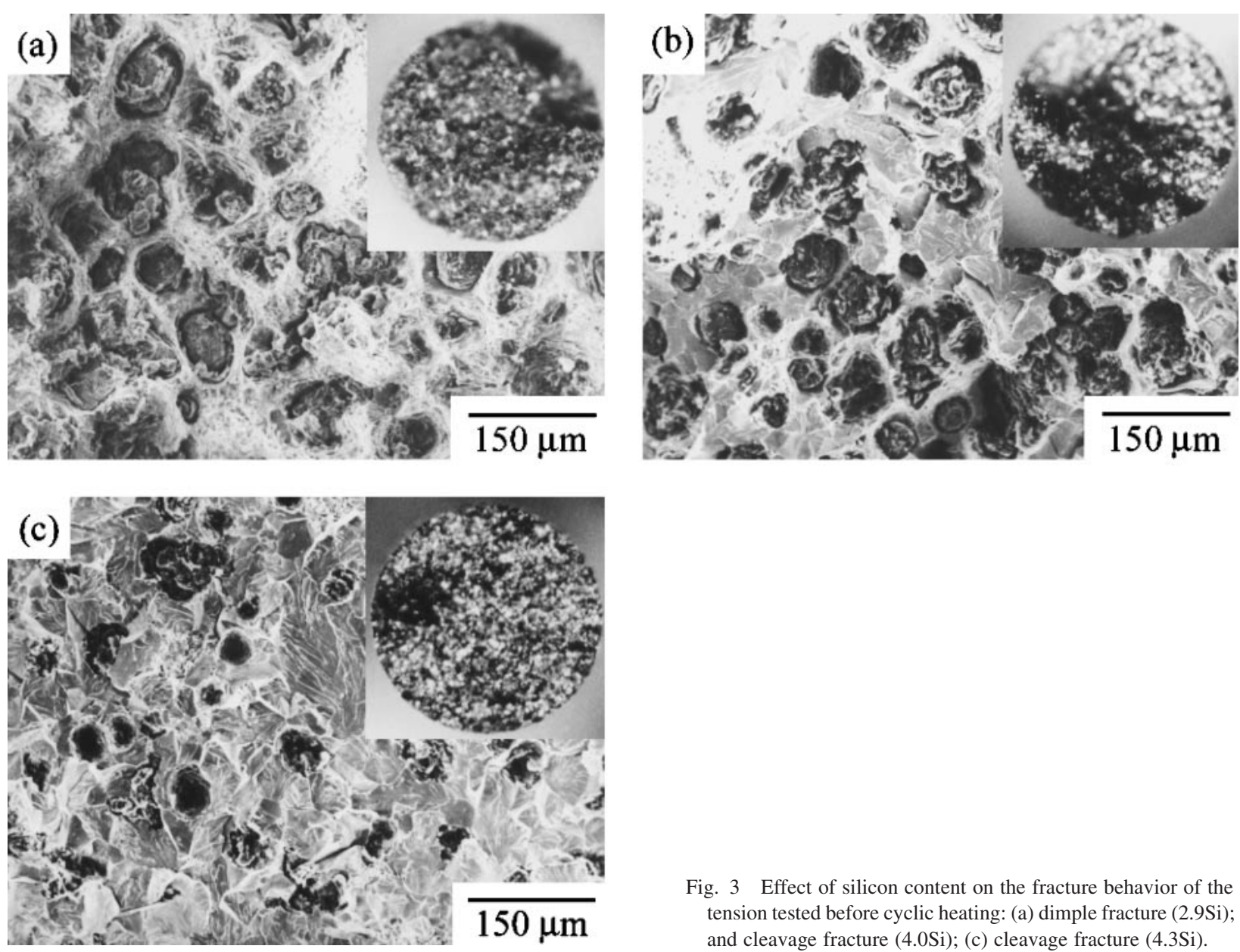

Fig. 3 Effect of silicon content on the fracture behavior of the specimens tension tested before cyclic heating: (a) dimple fracture (2.9Si); (b) dimple and cleavage fracture $(4.0 \mathrm{Si})$; (c) cleavage fracture $(4.3 \mathrm{Si})$. 


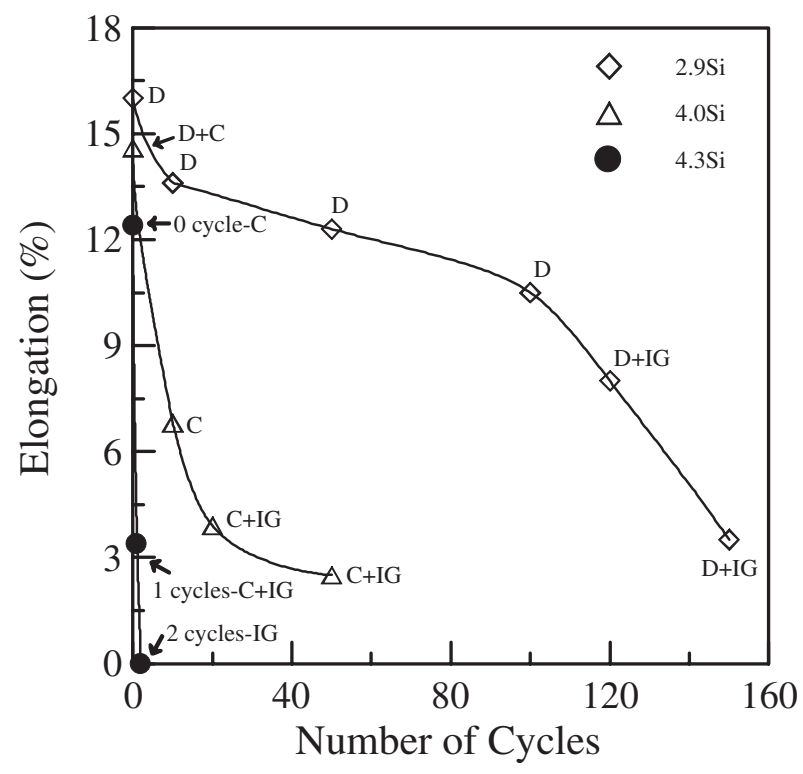

Fig. 4 Plot of elongation against the number of thermal cycles. (D: dimple fracture; C: cleavage fracture; IG: intergranular fracture).
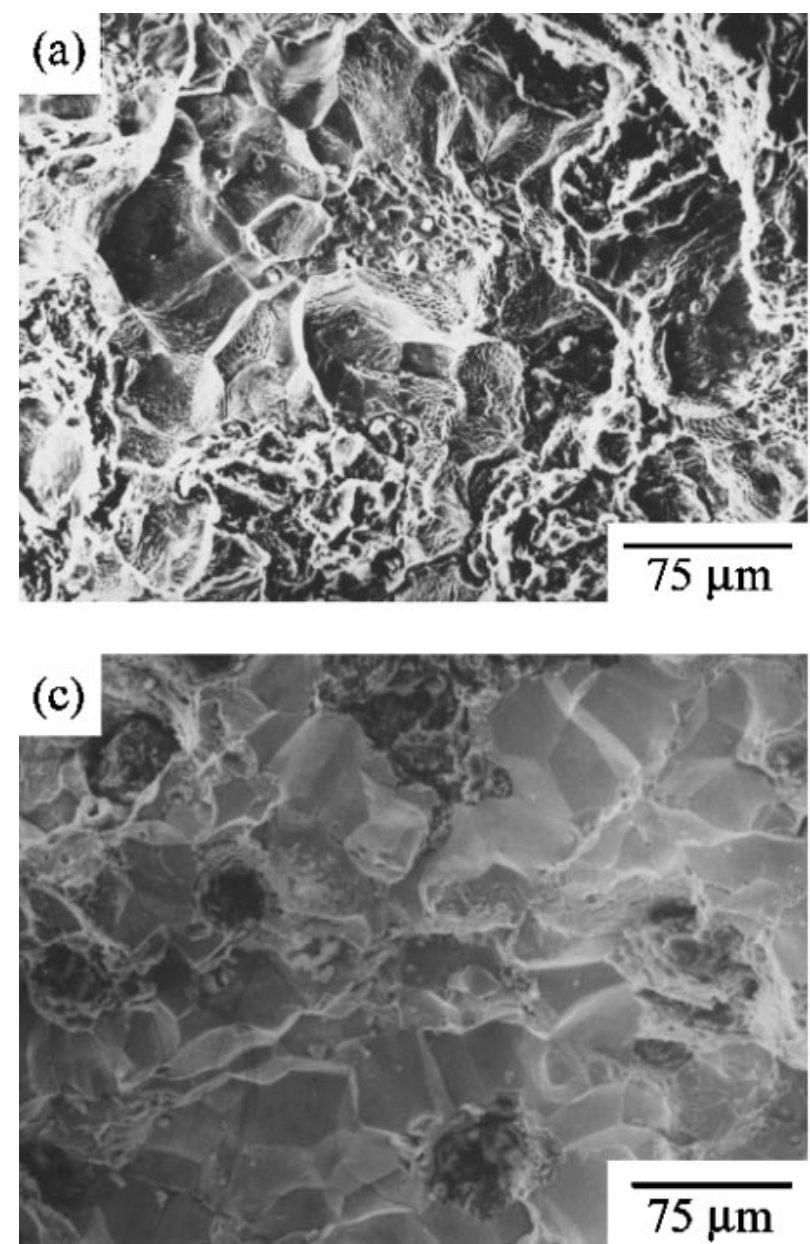

Figure 5 demonstrates that the tensile fracture feature after the specimens suffered from a certain number of heating cycles is closely related to the above-mentioned two factors. A typical example, shown in Fig. 5(a), indicates that a fair large area fraction of intergranular fracture surface observed in the 2.9Si specimen after 150 thermal cycles. Notably, the clustered inclusions clearly concentrate and are embedded near the eutectic cell-wall region, located between graphite nodules, as shown in Fig. 6(a). Moreover, secondary dimple voids are also commonly observed on the intergranular fracture facets, as shown in Figs. 5(b) and 6(a).

Though Figs. 5(c) and 5(d) show very few differences between the intergranular fracture feature of the 4.0Si and that of the $4.3 \mathrm{Si}$ specimen, the initiation condition of intergranular fractures is distinctly different as shown in Fig. 4, that the inetrgranular fracture is initiated earlier as the silicon content is increased. For instance, the experimental data corresponds to 50 cycles for $4.0 \mathrm{Si}$ and 2 cycles for $4.3 \mathrm{Si}$ respectively. Figure 5 shows the consequences of intergranular fracture features, which can be further compared to the elongation data of Fig. 4. Furthermore, the area fraction of the intergranular fracture in the fracture surface tends to expand as the number of heating cycles increases. The $2.9 \mathrm{Si}$
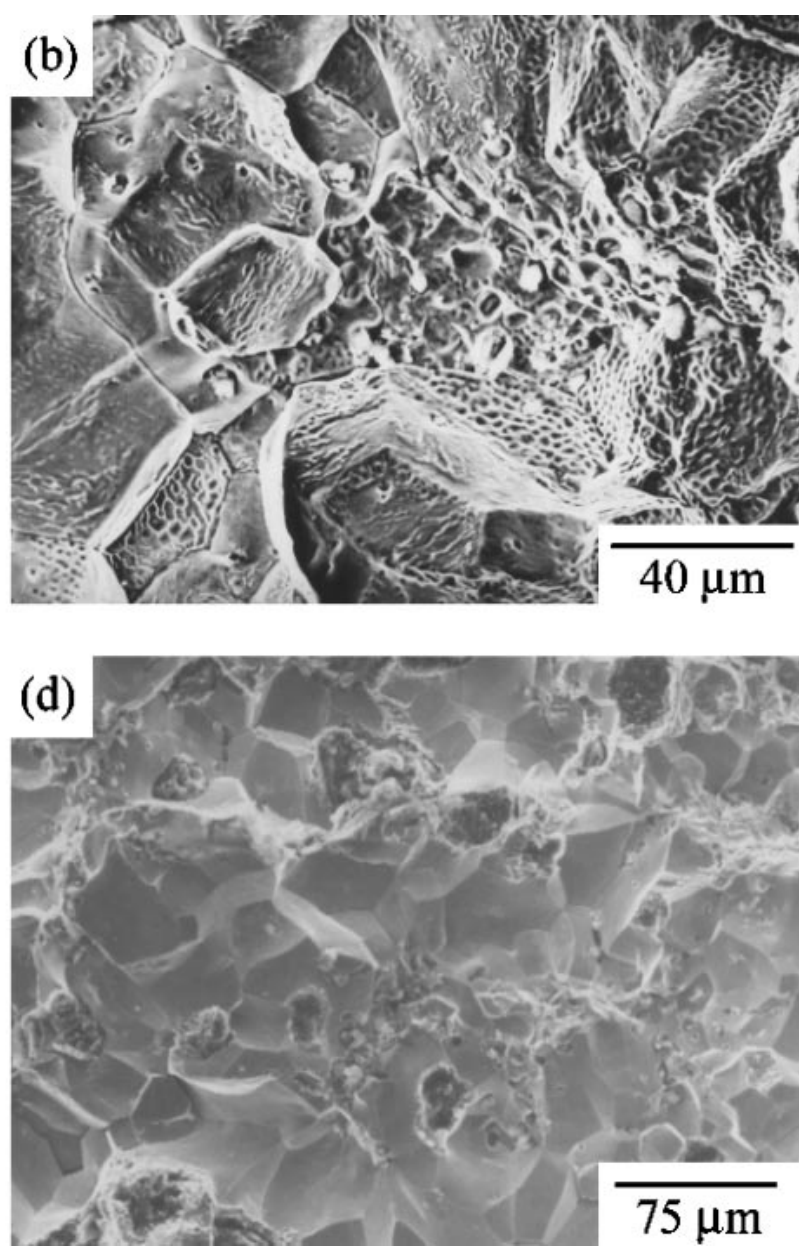

Fig. 5 Intergranular fracture of the specimens tension tested after cyclic heating: (a) 150 cycles (2.9Si); (b) 150 cycles with secondary dimples of the $2.9 \mathrm{Si}$ specimen; (c) 50 cycles $(4.0 \mathrm{Si})$ and (d) 2 cycles $(4.3 \mathrm{Si})$. 

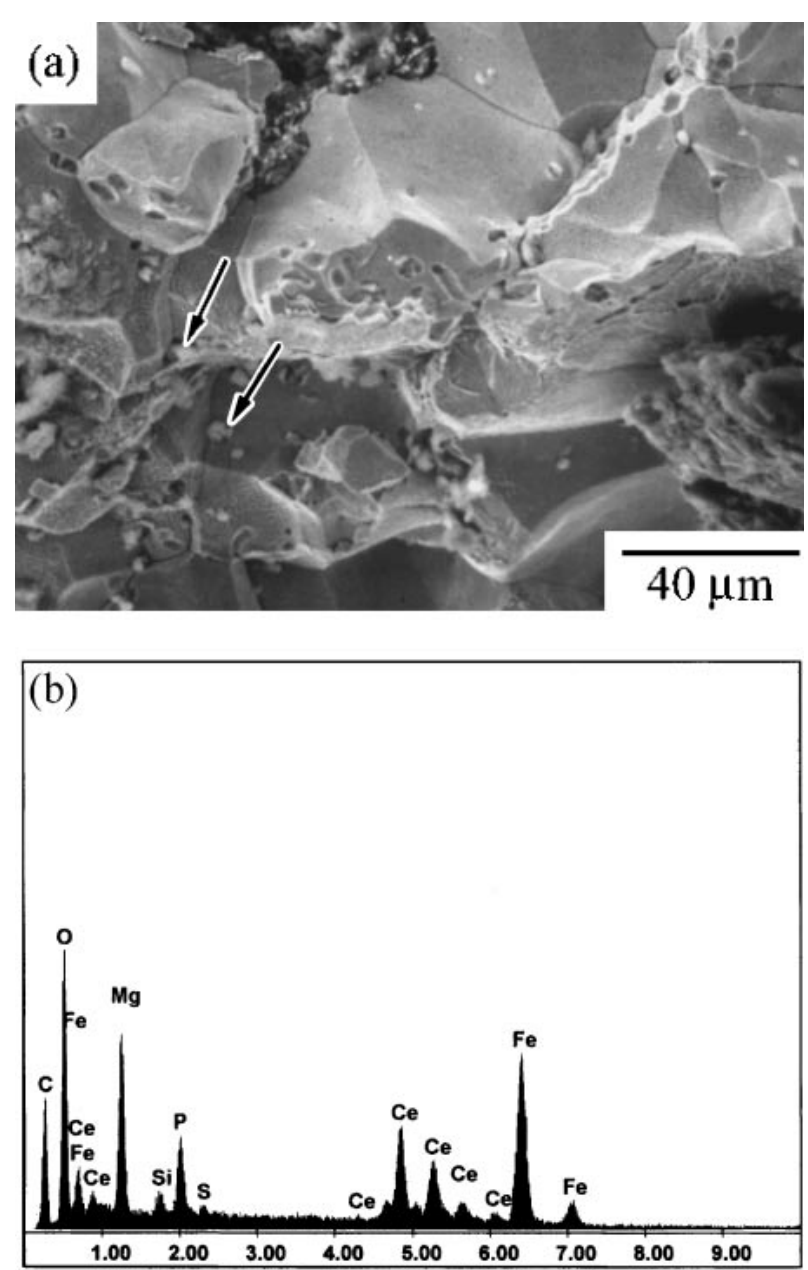

Fig. 6 (a) Intergranular fracture and concentrated inclusions in the eutectic cell wall region of the 4.0Si-50 cycles specimen with SEM; (b) EDS spectrum of the inclusions in the eutectic cell wall regions. Marked by arrows in fractography.

and 4.0Si specimens are further compared after both have suffered 50 heating cycles. Clearly, the fracture surface of the 4.0Si specimen changes from a mixed dimple and cleavage pattern to an evident intergranular fracture pattern, while the 2.9Si specimen still retains an entirely ductile dimple pattern.

The occurrence of an intergranular fracture depends strongly on the microstructural feature of eutectic cell boundaries. ${ }^{2,6,7)}$ Figure 6(a) shows a fair amount of inclusion particles embedded in the cell wall region, the inclusion particles marked by arrows are elucidated. EDS analysis data indicate that they are a kind of oxide, composed mainly of magnesium, phosphorus and cerium, as shown in Fig. 6(b). Furthermore, the intergranular fracture facets with the secondary dimple voids are a kind of typical feature. The area in Fig. 7(a) mainly indicates magnesium and oxygen peaks, shown in Fig. 7(b). As the location of voids neighbor on the central region of the eutectic cell boundary, the secondary dimple voids tend to disappear on the intergranular fracture facets (as shown in Fig. 8(a)), but the magnesium and oxygen peaks can still be detected (as shown in Fig. 8(b)). For confirmation, an Auger microprobe was used to analyze further the above-mentioned smooth facets, and the facets with secondary dimple voids on the intergranular fracture
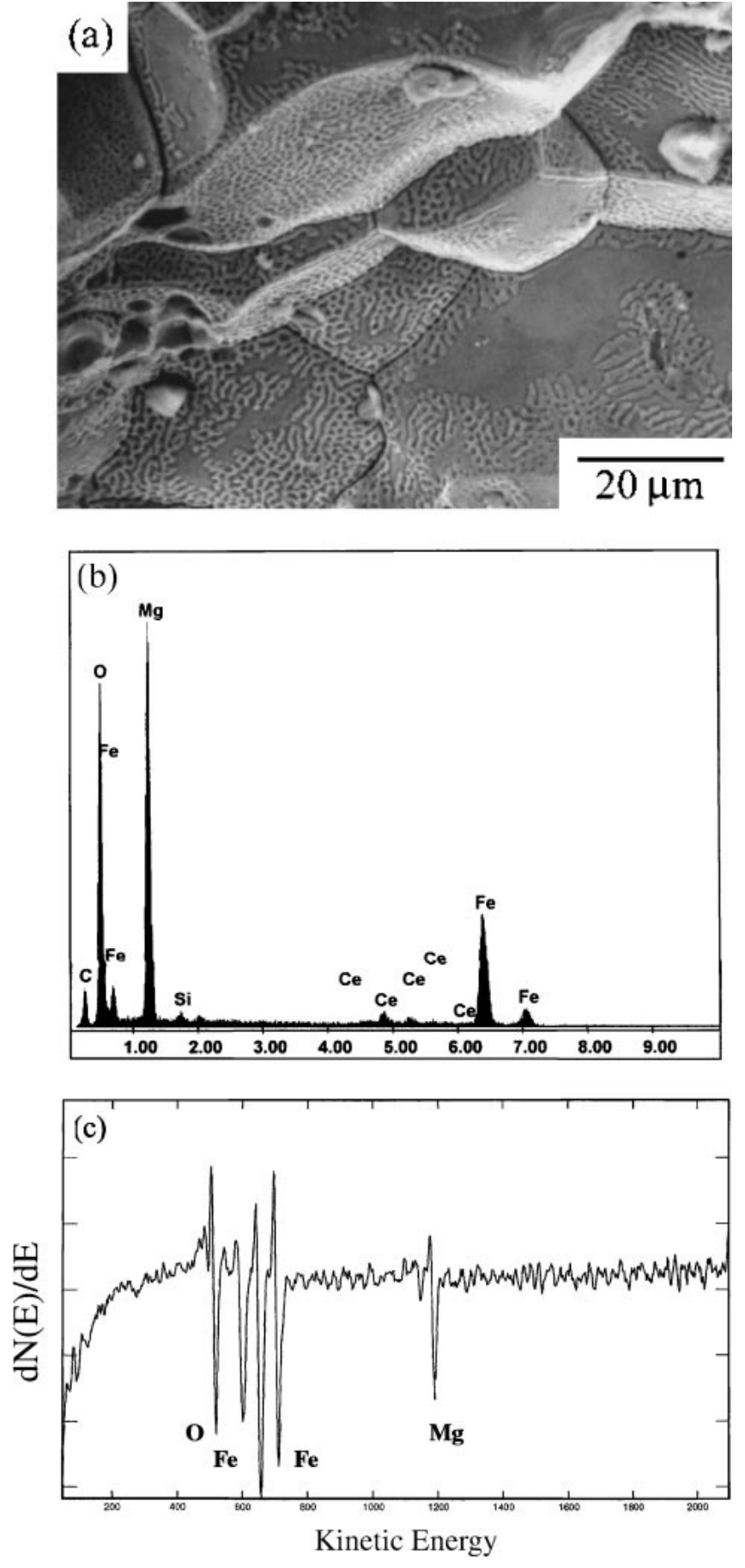

Fig. 7 (a) Secondary dimple voids of the 4.0Si-50 cycles specimen; (b) EDS spectrum on the surface of the secondary dimple voids; (c) AES spectrum on the surface of the secondary dimple.

facets. Figures 7(c) and 8(c) display the Auger spectra from the secondary dimple voids and smooth intergranular fracture facets. Figure 9(a) clearly shows that the Auger peaks of magnesium detected on the secondary dimple voids follow the locus of the oxidation state of magnesium element, in a shift of the kinetic energy of the valence level. The results shown in Fig. 9(b) can be further compared to that in Fig. 9(a). 

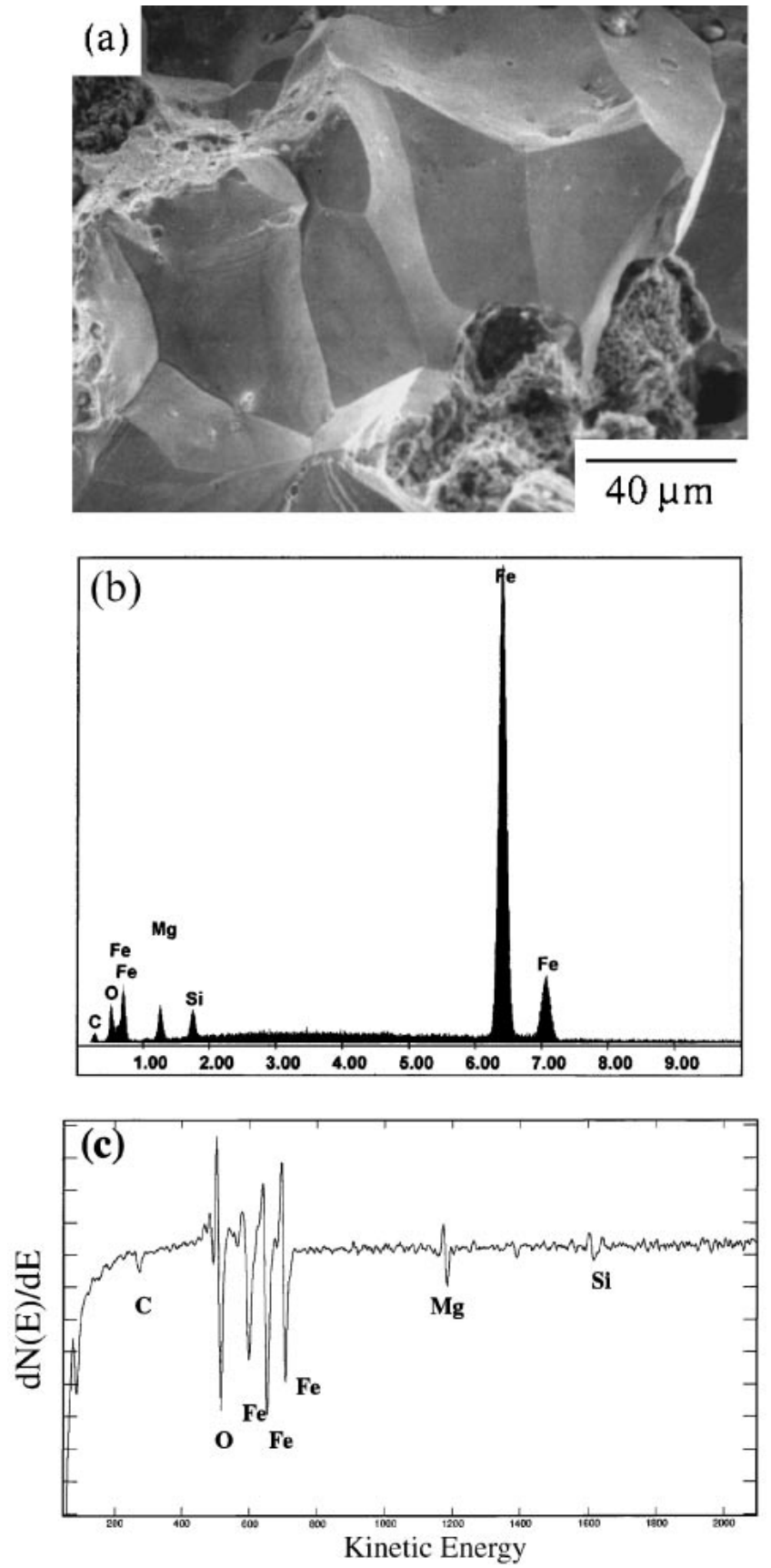

Fig. 8 (a) Smooth intergranular fracture facets of the 4.0Si-50 cycles specimen; (b) EDS spectrum on the surface of the smooth facets; (c) AES spectrum on the smooth facets.

\section{Discussion}

Based on the observation evidences as presented in Figs. 6 and 7 , internal oxidized inclusions, consisting of magnesium, phosphorus and cerium, were embedded in each eutectic cell wall region as shown in Fig. 10(a). Outside this region, a distinct amount of metallic magnesium can be detected; therefore, some metallic magnesium caused internal oxidation during the cyclic heating test. Intergranular cracks can be directly identified that initiated from the clusters of inclusions (Fig. 10), and the major cause of the tensile embrittlement of ferritic SG cast irons is closely related to the solidificational microstructure feature. ${ }^{2,6)}$

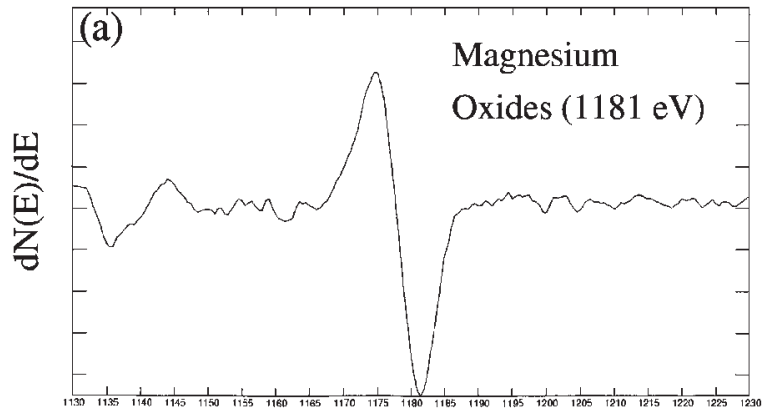

Kinetic Energy

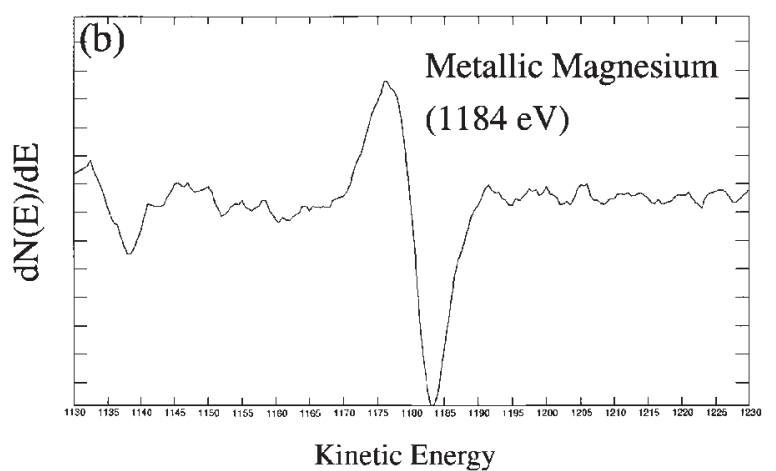

Fig. 9 Different AES spectra of magnesium as function of their kinetic energy for: (a) magnesium oxide on the surface of the secondary dimple voids and (b) metallic magnesium on the surface of the smooth facets.
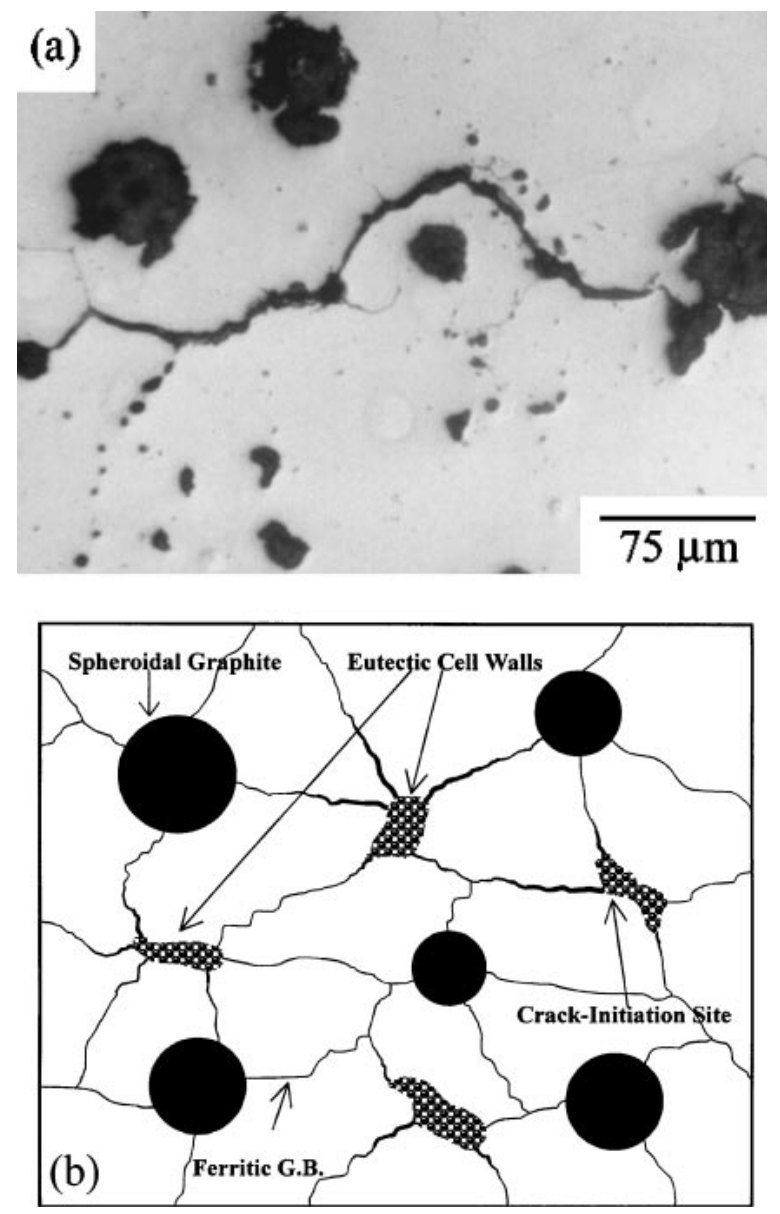

Fig. 10 (a) Microstructure obtained from the interrupted test of cracks initiated from the cell well region of SG cast irons after cyclic heating and (b) Schematic diagram. 
Gaseous element in cast iron melt are well known factor to cause casting defects such as blowholes and pinholes in the castings during the eutectic solidification process, oxygen often concentrates in the eutectic liquid to enhance gas defects. However the oxygen content will be raised up as increased silicon content, ${ }^{9)}$ consequently, the formation of secondary dimple voids on the intergranular facets can be recognized, it stands to reason that the intergranular embrittlement can suggest to be related to internal oxidation during cyclic heating process.

The effects of the silicon content on the tensile intergranular embrittlement after the specimens suffered from a certain number of heating cycles were discussed. As shown quantitatively in Fig. 4, the deterioration of tensile elongation with depends strongly on the number of heating cycles, silicon content and microstructural features of the eutectic cell boundary. The maximum stress occurs between graphite nodules where the oxide inclusions have clustered. ${ }^{10)}$ The region of the clustered oxide inclusions is rather irregular and tends to concentrate in the central region of the eutectic cell boundaries. Notably, small variations in clustered oxide inclusions can cause significant changes in mechanical properties. Tensile strain hardening rate and $n$ value as depicted in Fig. 11 show that the overall effect of these hetergenerous oxide inclusions on tensile deformation feature can be recognized, pertaining to the microstructural evolution of eutectic cell boundaries. Figure 11(a) indicates that both $4.0 \mathrm{Si}$ and $4.3 \mathrm{Si}$ specimens have a higher strain hardening rate than the $2.9 \mathrm{Si}$ specimen, particularly at the initial stage of tensile deformation. The rate changes continuously over a specific true strain value, the strainhardening rate of high silicon content samples (4.0Si and 4.3Si) drastically drops to the rate even lower than that of 2.9Si specimen.

These observations agree well with the microstructural evolutions discussed in the previous sections. Furthermore, the variation of $n$ value during tensile deformation also reflects inhomogeneous local yielding. A comparison can be made between two 2.9Si specimens, one that suffered cyclic heating and the other without suffered cyclic heating. Figure 11(b) reveals the decline of the specimens after suffered a certain number of thermal cycles. As the silicon content increases, this region is the final solidification region for higher concentration segregation. Consequently, the morphology of eutectic cell boundary and the degree of magnesium segregation become significantly different that affect the internal oxidation factor during the specimen suffers cyclic heating. However the presence of oxidized inclusion particles may play an important role in the variation of $n$ value as shown in Fig. 11(b).

Concerning the area with smooth intergranular facets (Fig. 8(a)) apart from the central region of the eutectic cell boundary, many previous reports have examined the effect of alloying elements on the strength of ferritic irons. ${ }^{9,10)}$ Silicon should be considered to be one of the elements that can reduce boundary strength in the ferrous matrix. McLean and Hondros $^{9)}$ point out that the critical fracture stress of materials tended to decreases as the silicon content increased.

However, since the ferritic grains are body center cubic structure, the fracture surfaces eventually change from a
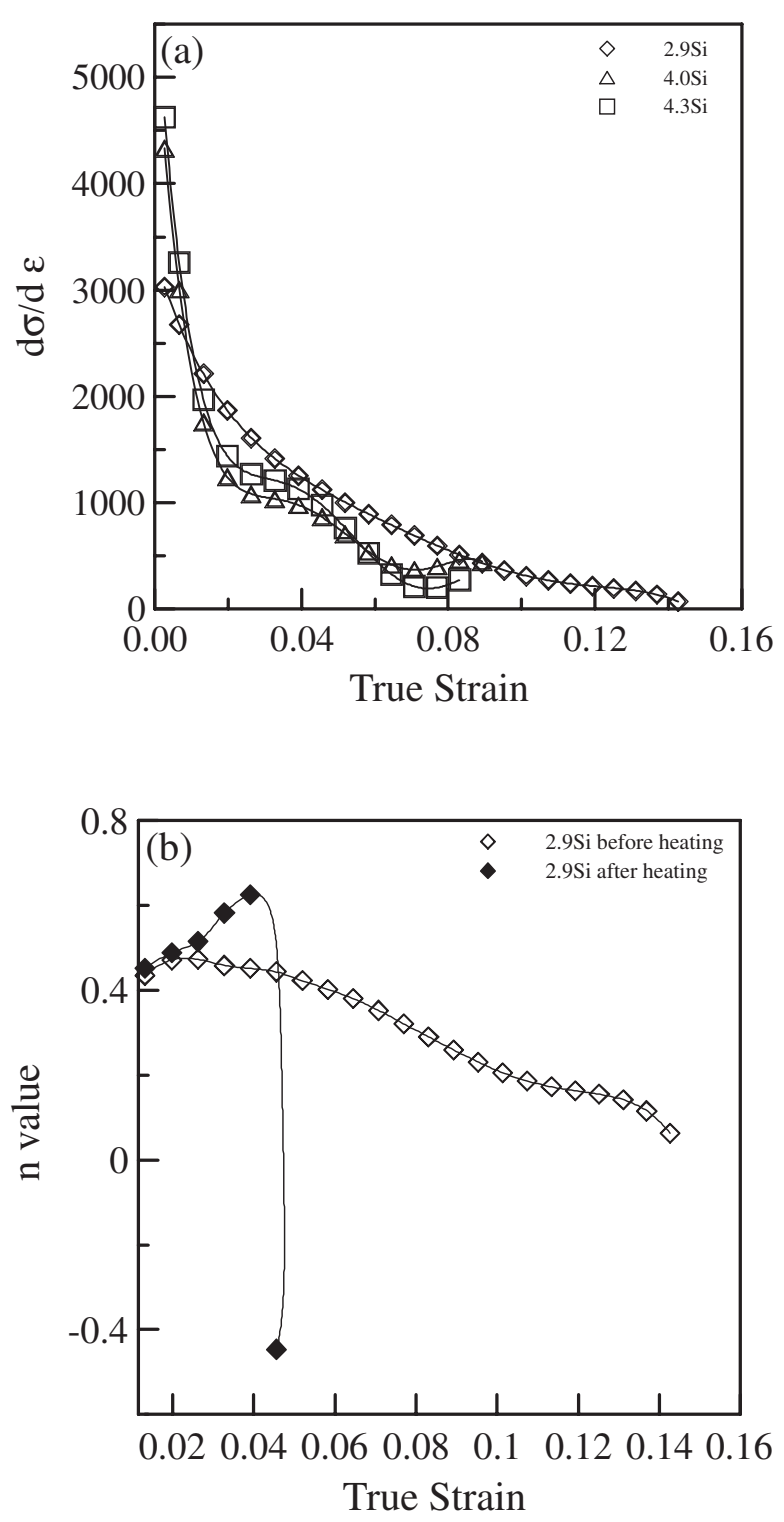

Fig. 11 (a) Strain hardening rate $\mathrm{d} \sigma / \mathrm{d} \varepsilon$ against true strain in the specimens, the $2.9 \mathrm{Si}, 4.0 \mathrm{Si}$, and $4.3 \mathrm{Si}$ specimens before cyclic heating; and (b) $n$ value against true strain in the specimen, which comparison with the $2.9 \mathrm{Si}$ specimen before and after cyclic heating.

dimple pattern to a cleavage pattern, as the silicon content is increased in a tension test before cyclic heating. ${ }^{11,12)}$ Additionally, the boundary strength tends to decrease as the silicon content or the number of thermal cycles increases. These results are also consistent with the above-mentioned microstructural evolution, involving intergranular fracture to cause the deterioration of tensile ductility.

Furthermore, increasing silicon content not only elevates the solid solution degree of the ferrite grains, but also narrows the morphology of the eutectic cell wall and concentrates the oxidized particles more densely in this region. Although adding silicon improves the microstructural stability at elevated temperatures, it also reduces the thermal conductivity, increasing the temperature gradient between the surface and the internal part. However, the experimental results indicate a ferritic SG cast iron's intrinsic vulnerability to cyclic heating, associated with the localization and concentration of damages, and initiating early cracking. 


\section{Conclusions}

(1) The tensile elongation of SG cast iron tends to decrease as the number of thermal cycles increases. The elongation deterioration rate increases with the silicon content.

(2) The fracture surface of specimen with lower silicon content (around 3.0Si) will change from a dimple pattern to a distinct intergranular fracture, whereas the 4.0Si and 4.3Si specimens changed from a brittle cleavage to an intergranular fracture, as the number of thermal cycles increased.

(3) The presence of magnesium, phosphorus and cerium containing oxidized inclusions in the eutectic cell boundaries, and the segregated magnesium atoms in the annealed ferrite grain boundaries are very closely related to the formation of oxidized inclusion during cyclic heating process. Experimental results show that the observed intergranular embrittlement of ferritic SG cast iron after cyclic heating process is consistent with the microstructural evolution that is closely related to the variation of silicon content.

\section{Acknowledgments}

This work was financially supported by the National Science Council of R.O.C. (Taiwan) for which we are grateful (Contract No. NSC 91-2216-E-006-043).

\section{REFERENCES}

1) C. P. Cheng, S. M. Chen, T. S. Lui and L. H. Chen: Metall. Trans. A 28A (1997) 325-333.

2) C. P. Cheng, T. S. Lui and L. H. Chen: Metall. Trans. A 30A (1999) 1549-1558.

3) K. Röehrig: AFS Trans. 86 (1978) 75-88.

4) Y. J. Park, R. B. Gundlach, R. G. Thomas and J. F. Janowak: AFS Trans. 93 (1985) 415-422.

5) M. C. Rukadikar and G. P. Reddy: AFS Trans. 97 (1989) 351-360

6) F. T. Shiao, T. S. Lui, L. H. Chen and S. F. Chen: Metall. Trans. A 30A (1999) $1775-1784$.

7) F. T. Shiao, T. S. Lui and L. H. Chen: Mater. Trans., JIM 39 (1998) 1033-1039.

8) S. Chang, D. Shangguan and D. M. Stefanescu: Metall. Trans. A 23A (1992) 1333-1344.

9) A. Kagawa, Y. Shimamoto and T. Okamoto: Materials Research Society, (Pittsburgh, Pennsylvania, USA, 1990) pp. 513-520.

10) J. F. Knott: Fundamental of Fracture Mechanics, (Butterworth \& Co. Ltd., London, 1973) pp. 27-29.

11) M. P. Seah and C. F. Lea: Philos. Mag. 31 (1975) 627-645.

12) E. D. Hondros and D. McLean: Physical Metallurgy, part I, (Elsevier Science Publishers B. V., 1983) pp. 913-920. 